\title{
Assumption-Simulation-Feedback-Adjustment (ASFA) Framework for Real-Time Correction of Water Resources Allocation: a Case Study of Longgang River Basin in Southern China
}

\author{
Shenlin $\mathrm{Li}^{1,2,3,4} \cdot$ Xiaohong Chen ${ }^{1,2,3} \cdot$ Vijay P. Singh ${ }^{4}$. \\ Yanhu $\mathrm{He}^{1,2,3}$
}

Received: 24 January 2018 / Accepted: 7 June 2018 /

Published online: 21 June 2018

(C) The Author(s) 2018

\begin{abstract}
Water resources allocation is subject to uncertain future conditions and therefore needs real-time correction. This study develops a framework of "assumption-simulationfeedback-adjustment" (ASFA) for real-time correction of water resources allocation. The assumption component constructs a water resources allocation model and generates initial allocation solution (IAS); the simulation component applies IAS in a real-time hydrological scenario; the performance information is input into the feedback component. Three feedback functions, including gain function, correlation function, and least square function, are employed to deal with the information, and the value of output gain is determined for the adjustment component. The result then is a feedback allocation solution (FAS). This study applied ASFA to Longgang River basin, China, as a case study, compared FASs generated by three different feedback functions as well as IAS. Results showed that FAS generated by the gain function (FAS_GF) performed better with a higher assurance rate and less risk of continuous water shortage. Results also showed that to achieve the same management requirement, FAS_GF had a lower requirement of the amount of diverted water, indicating that the ASFA framework can make better use of water resources and reduce the pressure of diverted water. The ASFA framework builds a feedback mechanism for real-time correction of
\end{abstract}

Xiaohong Chen

eescxh@mail.sysu.edu.cn

1 Center for Water Resources and Environment, Sun Yat-sen University, Guangzhou 510275, China

2 Guangdong Engineering Technology Research Center of Water Security Regulation and Control for Southern China, Sun Yat-sen University, Guangzhou 510275, China

3 Key Laboratory of Water Cycle and Water Security in Southern China of Guangdong High Education Institute, Sun Yat-sen University, Guangzhou 510275, China

4 Department of Biological and Agricultural engineering, Texas A\&M University, College Station, TX 77843 , USA 
water resources allocation, provides a novel perspective for addressing the challenge of future uncertainty, which significantly improves the solutions of water allocation.

Keywords Water resources allocation · Feedback · Real-time correction · Longgang River basin

\section{Introduction}

Water resources allocation is an essential part of local water resources management. However, the performance of allocation solutions is affected by future uncertain scenarios. Under unexpected supply or demand, allocation solutions may be less than satisfactory. How to cope with the uncertainty of future supply and demand and how to generate a satisfactory allocation solution is a new challenge for water resources management.

To address the challenge, many researchers contributed from different perspectives. The major research focuses included the reduction of uncertainty, strengthening the robustness of allocation solutions, and real-time correction. The reduction of uncertainty entails the awareness of hydrologic nonstationarity. Stationarity is the idea that hydrologic variables have a time-invariant probability density function, with which the properties of future conditions can be estimated from the historical record, and the risks of water supply can be evaluated and managed (Milly et al. 2008). However, global climate change and anthropological interventions have caused increasing change and variability of hydrological variables, and the assumption of stationarity has been questioned or even pronounced "dead" (Milly et al. 2008; Galloway 2011; Bayazit 2015).

Many investigations aim to rebuild the stationarity of hydrologic time series and rework the traditional allocation methods based on the series (Schmocker-Fackel and Naef 2010). Westra et al. (2014) presented a framework for diagnosing and interpreting hydrological nonstationarity to improve the predictive ability of hydrological models. Raje and Mujumdar (2010) presented a modeling framework for effectively constraining uncertainty, using a measure of performance of general circulation models in simulating natural regimes. Coulibaly and Baldwin (2005) proposed an optimal dynamic recurrent neural network to directly forecast different nonstationary hydrological time series. Several investigators have recently discussed nonstationarity and the resulting uncertainty (Cohn and Lins 2005; Shao and Li 2011; Serinaldi 2015). However, how to judge the nonstationarity of hydrologic time series and whether a rebuilt series is stationary have not been concluded. As a result, allocation solutions generated from the "rebuilt series with stationarity" still face the challenge of practical application.

Robust decision making (RDM) focuses on forecasting future conditions to search an "optimal" solution. It considers that future condition represents a wide range of plausible states. The "optimal" solution under one state would be suboptimal if the state changes (Bankes 2002; Herman et al. 2014). Hence, RDM discusses the decision performance in a vast state of future scenarios and chooses a performance as a robust decision to face the future uncertainty (Steinschneider and Brown 2012; Herman et al. 2014). Groves and Lempert (2007) identified key scenarios which are most important to the decision makers and found such cases with statistical analysis to generate a robust long-term water planning in California. Lempert and Groves (2010) used simulation models to assess the performance of agency plans over thousands of plausible futures, helping the Inland Empire Utilities Agency (IEUA) explicitly develop adaptive policies to respond to climate change and integrating these policies 
into the organizations' long-range planning process. Herman et al. (2014) developed a multiobjective RDM to discover key tradeoffs between water supply alternatives and their robustness to uncertainties and applied it in North Carolina, U.S., for evaluating regional water supply portfolios for four water utilities.

Real-time correction addresses the uncertain condition by shifting a predesigned solution to an adjustable one. It is a common strategy in flood forecasting (Madsen and Skotner 2005; Heidari et al. 2006; Blöschl et al. 2008). However, real-time correction of water allocation solutions has not been widely investigated, as (1) the uncertain condition has not usually been considered as water demands are not so variable; and (2) the real-time feedback information is hard to acquire. However, nowadays, rapidly changing environmental conditions and complicated development of social and economic systems aggravate the pressure of uncertain water supply and demand, which requires managers to make corrections of former allocation solutions to adapt to new scenarios. On the other hand, water resources management electronic detection system is more common and real-time information is easier to obtain, which allows the feasibility of real-time correction.

Therefore, this study presents a feedback process for real-time correction of water resources allocation to generate a more accurate and efficient solution. The framework is built on the basis of common allocation method, which generates an initial allocation solution as an assumption plan. The performance of the initial allocation, such as allocation differences, is fed back to generate a value of gain with designed feedback functions. The gain then is used to adjust the initial solution to a correction one. We summarize the process as "assumption-simulation-feedback-adjustment" (ASFA). The ASFA framework was used in Longgang River basin as a case study. Results demonstrated that the feedback mechanism of ASFA framework worked efficiently for real-time correction of water resources allocation. The ASFA framework addresses the challenge of future uncertainty well, and is promising for wide application.

\section{Methodology}

\subsection{ASFA Framework}

The core idea of feedback allocation is to constitute a feedback loop which follows the route of "assumption-simulation-feedback-adjustment" (ASFA). The framework of ASFA is shown in Fig. 1. The assumption component defines the water resources allocation problem and generates initial allocation solutions (IAS) with a conventional method. The simulation component applies IAS to a real-time hydrological scenario. As scenario uncertainty, the difference series $(\operatorname{dif}(\mathrm{t}))$ between IAS and real-time water demand is generated. The feedback component processes $\operatorname{dif}(\mathrm{t})$ as a gain value with some design functions. The efficiency of feedback functions is the key part of ASFA. The adjustment component uses the gain value to correct IAS as a feedback allocation solution (FAS). The whole ASFA framework is operated in MATLAB.

\subsection{The Assumption}

The assumption is the first part of the ASFA framework. The part generates an initial allocation solution, which was assumed as a practicable one. We forecasted future water demands, 


\section{Assumption}

Constructing water resources allocation model for study area, generating initial water resources allocation solutions with conventional method under pre-set scenarios

\begin{tabular}{|c|c|c|c|}
\hline $\begin{array}{l}\text { Forecasting demands } \\
\qquad \mathrm{D}_{\mathrm{n}}: \mathrm{n}=1, \ldots, \mathrm{e} \\
\text { water demand for } \\
\text { industrial, municipal and } \\
\text { environmental use }\end{array}$ & $\begin{array}{l}\text { Defined objectives } \\
\qquad \mathrm{O}_{\mathrm{k}}: \mathrm{k}=1, \ldots, \mathrm{j} \\
\text { - maximizing economic output } \\
\text { - maximizing satisfied demand } \\
\text { - minimizing reservoir storage } \\
\text { alteration }\end{array}$ & $\begin{array}{l}\text { Defined constrains } \\
\qquad \mathrm{C}_{\mathrm{i}} \text { : } \quad \mathrm{i}=1, \ldots, \mathrm{h} \\
\text { - water balance constrain } \\
\text { - water supply security } \\
\text { constrain } \\
\text { - minimum satisfied demand }\end{array}$ & $\begin{array}{l}\text { Conventional } \\
\text { allocation method } \\
\text { - The Genetic } \\
\text { method was } \\
\text { selected in this } \\
\text { paper }\end{array}$ \\
\hline
\end{tabular}

\section{Simulation}

Applying Initial allocation solution (IAS) in real time reality hydrological scenarios, record the allocation difference $\left(\right.$ dif $\left._{\mathrm{t}}\right)$ between initial allocation solutions and real time water demand (RTD)

${\text { dif } f_{\mathrm{t}}=\mathrm{IAS}_{\mathrm{t}}-\mathrm{RTD}_{\mathrm{t}}}_{\substack{\text { Performance information: } \text { dif }_{\mathrm{t}} \& \mathrm{RTD}_{\mathrm{t}} \\ \downarrow}}$

\section{Feedback}

Using designed functions to generate a gain value as feedback index from $\operatorname{dif}_{t}, \mathrm{RTD}_{\mathrm{t}}$ and $\mathrm{IAS}_{\mathrm{t}}$, to form the feedback allocation solution (FAS) at next time step.

\begin{tabular}{|c|c|c|}
\hline Gain function & $\bullet$ Correlation function & Least square function \\
\hline gain $_{\mathrm{t}+1}=\mathrm{Kr} * \operatorname{dif}_{\mathrm{t}}+\mathrm{Kd} * \varsigma$ & $\mathrm{RTD}_{\mathrm{t}+1}=\mathrm{a}^{*} \mathrm{IAS}_{\mathrm{t}+1}+\mathrm{b}$ & $d i f_{\mathrm{t}+1}=\mathrm{a} *(\mathrm{t}+1)+\mathrm{b}$ \\
\hline $\mathrm{FAS}_{\mathrm{t}+1}=\mathrm{IAS}_{\mathrm{t}+1}+$ gain $_{\mathrm{t}+1}$ & $\mathrm{FAS}_{\mathrm{t}+1}=\mathrm{RTD}_{\mathrm{t}+1}$ & $\mathrm{FAS}_{\mathrm{t}+1}=\mathrm{IAS}_{\mathrm{t}+1}+d i f_{\mathrm{t}+1}$ \\
\hline $\begin{array}{l}\mathrm{Kr} \& \mathrm{Kd} \text { are characters waiting for } \\
\text { calibration; } \varsigma \text { is noisiness }\end{array}$ & $\begin{array}{l}\text { a \& b are characters yield by correlation } \\
\text { analysis between RTD and IAS }\end{array}$ & $\begin{array}{l}d i f_{\mathrm{t}}=\mathrm{a} *(\mathrm{t})+\mathrm{b} \text { is the regression } \\
\text { function of } \text { dif } \text { and } \mathrm{t} \text {. }\end{array}$ \\
\hline
\end{tabular}

Feedback allocation solutions (FAS)

\section{Adjustment}

Adjust IAS as FAS. Moreover, the constraints defined in the assumption part still work, a test of whether the FAS satisfied the constraints is also required in this part.

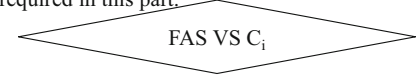

Fig. 1 Framework of ASFA. ASFA includes "assumption-simulation-feedback-adjustment." The feedback is the key part. This paper designed three feedback functions, including gain function, correlation function, and least square function. The allocation solutions from all the three functions, as well as the initial one, are compared to their performances

defined objectives, decision variables, and constraints to construct a water resources allocation model, and applied genetic programming to determine an IAS.

\section{(1) Defining water resources demands.}

The main demands and their forecasts, as well as their water use efficiency are defined first, and the basic water consumption system is established. The demands are usually from industrial, municipal, and environmental users. Their forecasts are usually according to historical records and local development prospects, and the artificial neural network is a popular method to do forecasting (Jain et al. 2001; Ghiassi et al. 2008; Adamowski 2008).

The forecast runoff was also generated which important to evaluate the amount of available water resources and the environmental demand (more details in the simulation part). 
(2) Defining objectives and constraints

The objectives, under which the method was established, are summarized below.

1) Maximize economic benefit

Agricultural, industrial, and municipal sectors are the general water users. Generally, their economic benefits are connected with the amount of supply water. Maximizing the total economic benefit is one of the most important objectives of water resources allocation. The objective function can be defined as follows:

$$
\operatorname{Max} W E=\max \sum_{t=1}^{n}\left(w_{n e}{ }^{*} q_{e}{ }^{t}+w_{n i}{ }^{*} q_{i}{ }^{t}+w_{n m}{ }^{*} q_{m}{ }^{t}\right)
$$

where $W E$ is the total economic benefit; $n$ is the number of time steps; $w_{n e}, w_{n i}$, and $w_{n m}$ are the weights assigned to environmental, industrial, and municipal users, respectively. They can be assigned as the net income per unit of water supply in a simple system; and $q_{e}{ }^{t}, q_{i}{ }^{t}$, and $q_{m}{ }^{t}$ are the water resources applied in these three fields at time point $t$, respectively.

\section{2) Maximize water supply}

The objective here is to satisfy all demands as far as possible. The objective function can be expressed as:

$$
\text { Max WS }=\max \left\{\sum_{t=1}^{n} \min \left(\frac{q_{e}^{t}}{q_{e n}^{t}}, 1\right)+\min \left(\frac{q_{i}^{t}}{q_{\text {in }}^{t}}, 1\right)+\min \left(\frac{q_{m}^{t}}{q_{m n}^{t}}, 1\right)\right\} / n
$$

where WS is the aggregated rate of water supply in the whole time period; and $q_{e n}{ }^{t}, q_{i n}{ }^{t}$, and $q_{m n}{ }^{t}\left(\mathrm{~m}^{3} / \mathrm{s}\right)$ are the discharge demands for environmental, industrial, and municipal users, respectively.

3) Maximize water quality

The objective here is to maximize water quality and the objective function can be defined as:

$$
\operatorname{Max} W Q=\max \sum_{t=1}^{n} \min \left\{\left(q_{s i}^{t}+q_{r o}^{t}+q_{t}^{t}-q_{c o n s}^{t}\right) / q_{q n}^{t}, 1\right\}
$$

where $W Q$ is the index of water quality at the control cross section; $q_{s i}{ }^{t}, q_{r o}{ }^{t}$ and $q_{t}{ }^{t}$ are the discharges at time $t$, from the land surface, reservoir outflow, and water transfer, respectively; $q_{\text {cons }}{ }^{t}$ is the water consumed; and $q_{q n}{ }^{t}$ is the discharge required to maintain an acceptable water quality in the river.

\section{4) Maximize reservoir storage}

Reservoirs are an important hydraulic structure in many areas that make substantial contributions to local water resources management plans. Maintaining ample storage is 
critical for reservoir operation. The variation in reservoir storage $(W R)$ can be expressed as:

$$
\operatorname{Max} W R=\max \sum_{t=1}^{n}\left(q_{r i}^{t}-q_{r o}^{t}\right) \Delta t
$$

Where $q_{r i}{ }^{t}$ and $q_{r o}{ }^{t}$ are the reservoir input and output discharges, respectively.

The optimization model satisfies the following constraints and mass balance equation (or continuity equation):

$$
V_{\min }<V_{t}<V_{\max }
$$

where $V_{\min }$ and $V_{\max }$ are the minimum and maximum storages of reservoir, respectively; and $V_{t}$ is the actual storage at time $t$.

$$
V_{t+1}-V_{t}=\left(q_{r i}^{t}-q_{r o}^{t}\right) \times \Delta \mathrm{t}
$$

and

$$
q_{e}^{t}+q_{i}^{t}+q_{m}^{t}<q_{r o}^{t}+q_{t}^{t}
$$

The water supply security constraints can be defined as:

$$
\theta_{a} \times q_{e n} \leq q_{e}^{t} \leq q_{e n}
$$

$$
\theta_{i} \times q_{\text {in }} \leq q_{i}^{t} \leq q_{\text {in }}
$$

$$
\theta_{d} \times q_{m n} \leq q_{d}^{t} \leq q_{m n}
$$

where $\theta$ is the minimum rate of supplied water, below which serious damage to local water security is incidental. The reservoir outflow constraint can be defined as:

$$
q_{r o}^{t}<\min \left(q_{c a p}, q_{s e c}\right)
$$

where $q_{c a p}$ is the maximum discharge capacity of the reservoir, and $q_{s e c}$ is the security discharge for the downstream flood control safety.

\section{(3) Genetic algorithm}

Genetic algorithm is one of the most popular multi-objective evolutionary algorithms. It can keep a multipoint perspective in the whole search space, avoiding being trapped in a local-optimal solution. Moreover, it requires no continuity-differentiability on objective functions, and has a good performance in problems with discrete decision variables (Morshed and Kaluarachchi 2000). Many researchers have applied it to water allocation problems (Davijani et al. 2016; Nouiri 2014; Elferchichi et al. 2009; Zahraie and Tavakolan 2009; Liu et al. 2010). The algorithm includes a random, parallel, and adaptive search procedure, based on the mechanics of natural selection that is utilized to search for the fittest solution to a problem with multiple objectives. 


\subsection{Simulation}

To evaluate the performance of allocation solution, we applied IAS to a real-time scenario for simulation. As the demand for industrial and municipal users has less uncertainty, only the environmental demand is discussed in the following part. Under future uncertainty, IAS does not meet the real-time demand perfectly. Taking Fig. 2 as an example, we assumed that target runoff for environmental use was $5 \mathrm{~m}^{3} / \mathrm{s}$, and the forecast natural runoff was shown as blue bars. Then, environmental demand was easy to calculate (e.g. the demand in January was $4 \mathrm{~m}^{3} / \mathrm{s}$, and demand in September was $1 \mathrm{~m}^{3} / \mathrm{s}$ ). In general, IAS will allocate water resources based on the forecast demands, so there was around $4 \mathrm{~m}^{3} / \mathrm{s}$ runoff allocated in January, and around $1 \mathrm{~m}^{3} / \mathrm{s}$ allocated in September. However, under future uncertainty, real runoff may be different from the forecast one. If real runoff was like what green bars showed in Fig. 2, then the actual demand in January would be only $2 \mathrm{~m}^{3} / \mathrm{s}$, and actual demand in September would be $3 \mathrm{~m}^{3} / \mathrm{s}$. As a result, IAS supplied a surplus allocation $\left(+2 \mathrm{~m}^{3} / \mathrm{s}\right)$ in January, and a deficit allocation $\left(-2 \mathrm{~m}^{3} / \mathrm{s}\right)$ in September. Such surplus and deficit allocation amounts generate the allocation difference series $\left(d i f_{t}\right)$, which we used for the next step.

\subsection{Feedback}

The feedback is a part to analyze the performance information from simulation, and yield the suggestion for correction of IAS. We designed three different feedback functions, including gain function (GF), correlation function (CR), and least square function (LS). All these three functions have the ability to forecast and maintain a quick reaction of new added data. Moreover, they are widely used in flood real-time correction (e.g. Cooper et al. 2018; Rahman et al. 2018; Liu et al. 2016). As a result, we applied them into real-time correction of water resources allocation, and compared their performances.

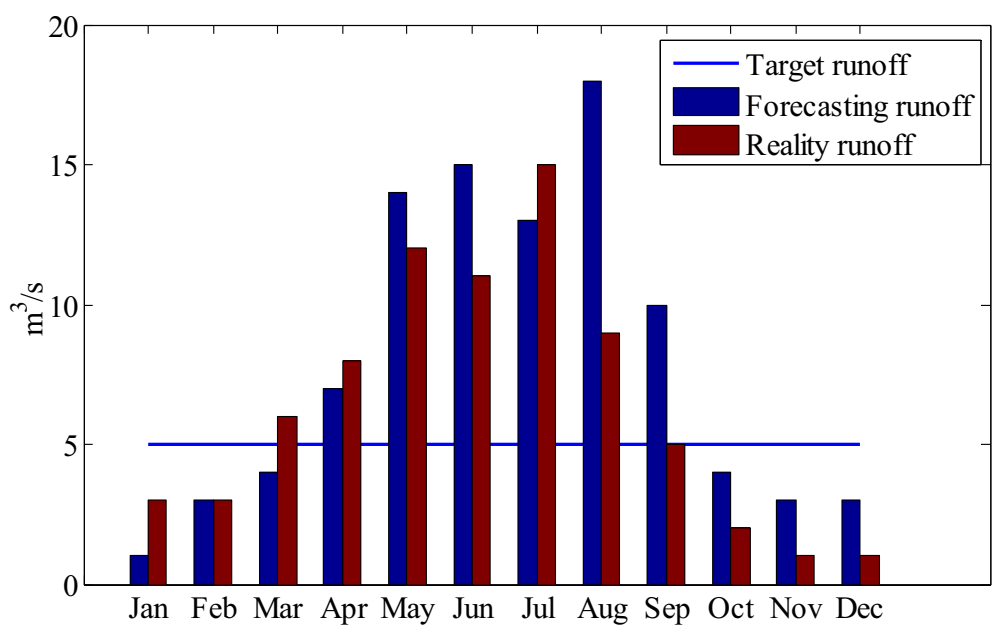

Fig. 2 An example of how allocation difference is generated under uncertain future scenario 


\subsubsection{Gain Function}

The design of gain function is under the idea that if there was a large positive (or negative) dif at time point $t$, the real demand $\mathrm{RTD}_{\mathrm{t}}$ would be smaller (or lager) than the forecast one, and such a status would be continuous at near time point $t+1$. As a result, the allocation solution at the next time point needs a negative (or positive) correction to make a better use of water resources. We called the amount of correction "gain value," and it was calculated as:

$$
\text { gain }=K r \times \operatorname{dif}_{t}+K d \times \in
$$

where $K r$ is the difference coefficient, $\epsilon$ is the noise disturbance, and $K d$ is the coefficient of $\epsilon$. Equation (12) shows that the feedback gain consists of a certain rate $(K r)$ of the allocation difference, and a disturbance (or noise) term. $\epsilon$ is a random value from $[-1,1]$. Coefficients $K r$ and $K d$ determine how important the difference and $\epsilon$ are in the feedback gain, respectively, and their value should also be optimized first to get a suitable gain function (we discussed it in Fig. 5). So the feedback solution can be shown as:

$$
\mathrm{FAS}_{t+1}=\mathrm{IAS}_{t+1}+\text { gain }
$$

\subsubsection{Correlation Function}

Correlation analysis is another idea for the design of feedback function. It is considered here that there was a correlation between IAS and RTD. We use the existing time series of IAS $_{t}$ and $\mathrm{RTD}_{\mathrm{t}}$ to determine a correlation function, so we can forecast $\mathrm{RTD}_{t+1}$ with $\mathrm{IAS}_{\mathrm{t}+1}$, and correct $\mathrm{FAS}_{\mathrm{t}+1}$ with the forecasted $\mathrm{RTD}_{\mathrm{t}+1}$. A correlation analysis is done first, and the correlation coefficient is calculated as:

$$
\mathrm{r}=\frac{\sum_{\mathrm{i}=1}^{\mathrm{n}}\left(\mathrm{IAS}_{\mathrm{i}}-\overline{\mathrm{IAS}}\right)\left(\mathrm{RTD}_{\mathrm{i}}-\mathrm{RTD}\right)}{\sqrt{\sum_{\mathrm{i}=1}^{\mathrm{n}}\left(\mathrm{IAS}_{\mathrm{i}}-\overline{\mathrm{IAS}}\right)^{2} \sum_{\mathrm{i}=1}^{\mathrm{n}}\left(\mathrm{RTD}_{\mathrm{i}}-\mathrm{RTD}\right)^{2}}}
$$

A linear correlation equation between IAS and RTD is generated as:

$$
\begin{gathered}
\mathrm{RTD}_{\mathrm{t}+1}=\mathrm{a}+\mathrm{b} * \mathrm{IAS}_{\mathrm{t}+1} \\
\mathrm{a}=\overline{\text { RTD }}-\mathrm{b} \overline{\mathrm{IAS}} \\
\mathrm{b}=\mathrm{r} \frac{\sigma(\mathrm{RTD})}{\sigma(\mathrm{IAS})}
\end{gathered}
$$

$\sigma(\mathrm{RTD})$ and $\sigma(\mathrm{IAS})$ are the mean square error of RTD and that of IAS, respectively.

Thus, the feedback allocation solution was corrected according to $\mathrm{RTD}_{\mathrm{t}+1}$ :

$$
\mathrm{FAS}_{t+1}=\mathrm{RTD}_{t+1}
$$


As time progresses, the nearest RTD will be fed back, and parameters $a$ and $b$ are updated over time. The core issue of applying such a function is to determine how long the IAS and RTD series should be fed back to calculate the correlation coefficient $r$. We used the series, from nearest 2 to nearest 60 time steps, to do correlation analysis, and compared the results to pick up the better size of the feedback series.

\subsubsection{Least Square Function}

The allocation difference series $\operatorname{dif}(\mathrm{t})$ is also a time series. Approaches for time series analysis can be used to structure a model for the dif(t) forecasting directly. The sum of forecast difference and initial allocation solution generates the feedback allocation solution, which is the core idea of the feedback correction.

We used a linear function as a regression function and built a linear relationship between dif and corresponding time point $t$ :

$$
\operatorname{dif}_{\mathrm{t}}=\hat{\mathrm{a}}+\hat{\mathrm{b}} \times(\mathrm{t})
$$

The least square method (Nakagawa and Koyanagi 1982; Chavent 1979) was used to estimate the function parameters $\hat{a}$ and $\hat{b}$, and then, a difference forecasting model was generated:

$$
\operatorname{dif}_{\mathrm{t}+1}=\hat{\mathrm{a}}+\hat{\mathrm{b}} \times(\mathrm{t}+1)
$$

The feedback allocation solution is:

$$
\mathrm{FAS}_{t+1}=\mathrm{IAS}_{t+1}+d i f_{\mathrm{t}+1}
$$

As in the CR function, parameters $\hat{a}$ and $\hat{b}$ are updated over time, and the optimization issue is the size of difference series. We input the series, from nearest 2 to nearest 60 time steps, to the least square method to estimate parameters $\hat{a}$ and $\hat{b}$, and compared the results to pick up the better size of the feedback series.

\subsection{Adjustment}

The Adjustment part focuses on checking whether FAS satisfied constraints defined earlier. As FAS output from the feedback part is a statistical result, it is necessary to verify that all FAS results are not beyond the constraint requirement. The final FAS can be adjusted as:

$$
\mathrm{FAS}_{t+1}=\operatorname{mid}\left\{\min (\mathrm{d}), \mathrm{FAS}_{t+1}, \max (\mathrm{d})\right\}
$$

where $\min (\mathrm{d})$ and $\max (\mathrm{d})$ define the constrained range of allocation amount, and $\mathrm{FAS}_{t+1}$ is the output feedback allocation solution from the Feedback part, and mid is a function to select the median value in the three numbers.

Another notable point is that the feedback adjustment in this article for one demand (e.g. environmental demand) does not influence the others (e.g. municipal demand), and does not require extra supply from reservoir. We just stored water resources from the surplus allocation and use the storage to adjust the deficit allocation, which is important to keep reservoir sustainable operation and protect the right of other demanders. 


\section{Study Area}

Longgang River basin, given in Fig. 3, was selected as a case study. The basin, with a latitude of 22.57 to $22.82^{\circ}$ north and a longitude of 114.15 to $114.43^{\circ}$ east, covers an area of $270 \mathrm{~km}^{2}$ (Fig. 3a), located in Shenzhen City, China. It is one of the most developed megacity areas in China. In the basin, nearly 1 million people inhabit, and more than 18.2 billion dollars GDP is created every year. Annual precipitation is around $1900 \mathrm{~mm}$. Rainy season is from April to September (Fig. 3b).

Water demand from the municipal and the industrial users was 127.67 million $\mathrm{m}^{3}$ and 78.55 million $\mathrm{m}^{3}$, respectively, in 2016, accounted for 57 and $35 \%$, respectively, of the total water demand. The sources of water were local rivers and reservoirs (accounting for 26.3\%), and diverted water from the diversion water projects (accounting for 68.7\%). Two large water diversion projects, the East Water Diversion Project and D-S Water Diversion Project, both pass through the basin. Existing five pipes connecting the basin and two water diversion projects are with a supply capacity of $1020 \mathrm{k} \mathrm{t} / \mathrm{d}$.

Another problem is poor water quality. Monthly COD data from 2008 to 2012 at the basin outlet section (Xiabei) is plotted as an example in Fig. 3c. Pollutant concentrations are much higher than the standard at almost all time points on the graph. The expectation for better water environment generates new additional water demand, making water resources allocation more challenging.

\section{Results}

To assess the performance of different feedback functions, we applied GF, CR, and LS, respectively, and quantified their allocation solution performance by two evaluation indexes. One is the cumulative probability curve $(\mathrm{CP})$ of satisfied demand, which presents the assurance rate of every satisfied demand; the other is the risk ratio curve (RR) of continuous water

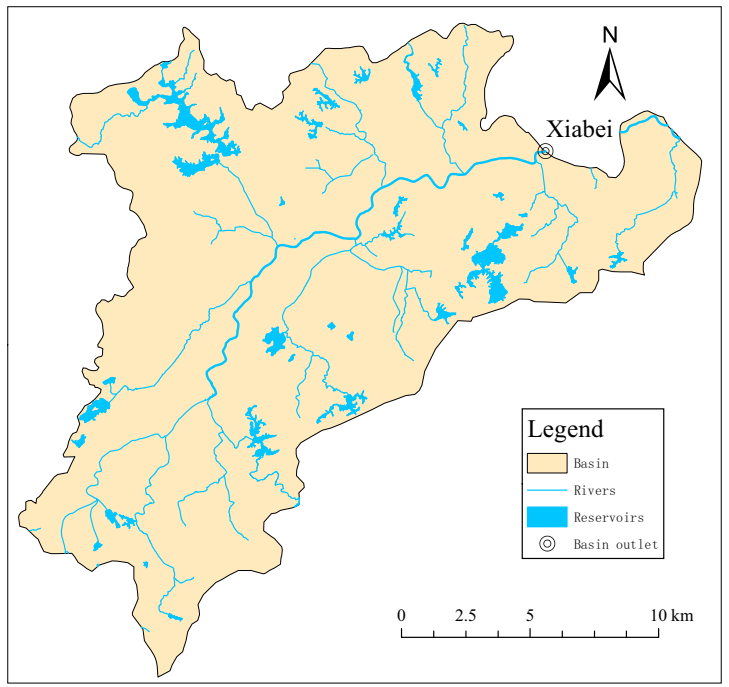

(a) Sketched map of Longgang River basin

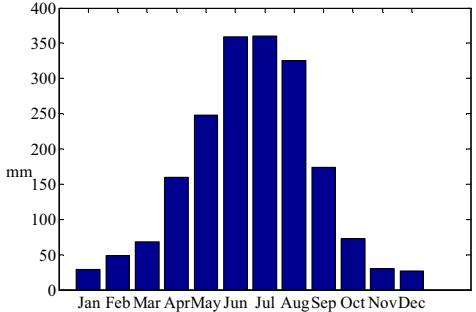

(b) Multi-year average precipitation

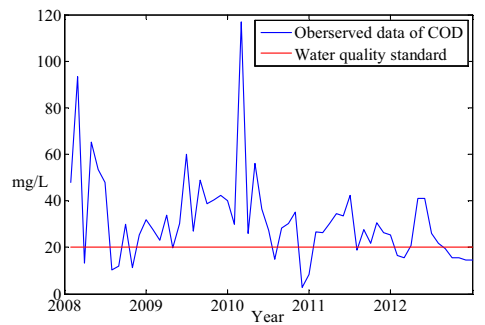

(c) Water quality in Xiabei

Fig. 3 (a) Sketched map of Longgang River basin; (b) Multi-year average precipitation in Longgang River basin; (c) Water quality in Xiabei 
shortage event, showing the occurrence risk of the event in different time durations. We defined the event when water shortage continuously appeared for more than 10 days. The two indexes illustrate the allocation solution performances by the amount dimension and time dimension, respectively.

Feedback allocation solutions (FAS) from three feedback functions are illustrated in Fig. 4. We optimized every function by assigning different values of function parameter, so every kind of function generated a bunch of FAS, which are shown as gray lines. The initial allocation solution (IAS) is compared as blue line.

We can see from Fig. 4a that there are higher values of CP in FAS_GF (feedback allocation solution generated with gain function) compared with IAS at every satisfied demand. Moreover, Fig. 4b illustrates that FAS_GF reduced RR significantly. Both of them indicated that gain function had the potential to generate better solutions than the initial one. Fig. $4 \mathrm{c}$ and $\mathrm{d}$ are the results of FAS_CR (feedback allocation solution generated with correlation function).
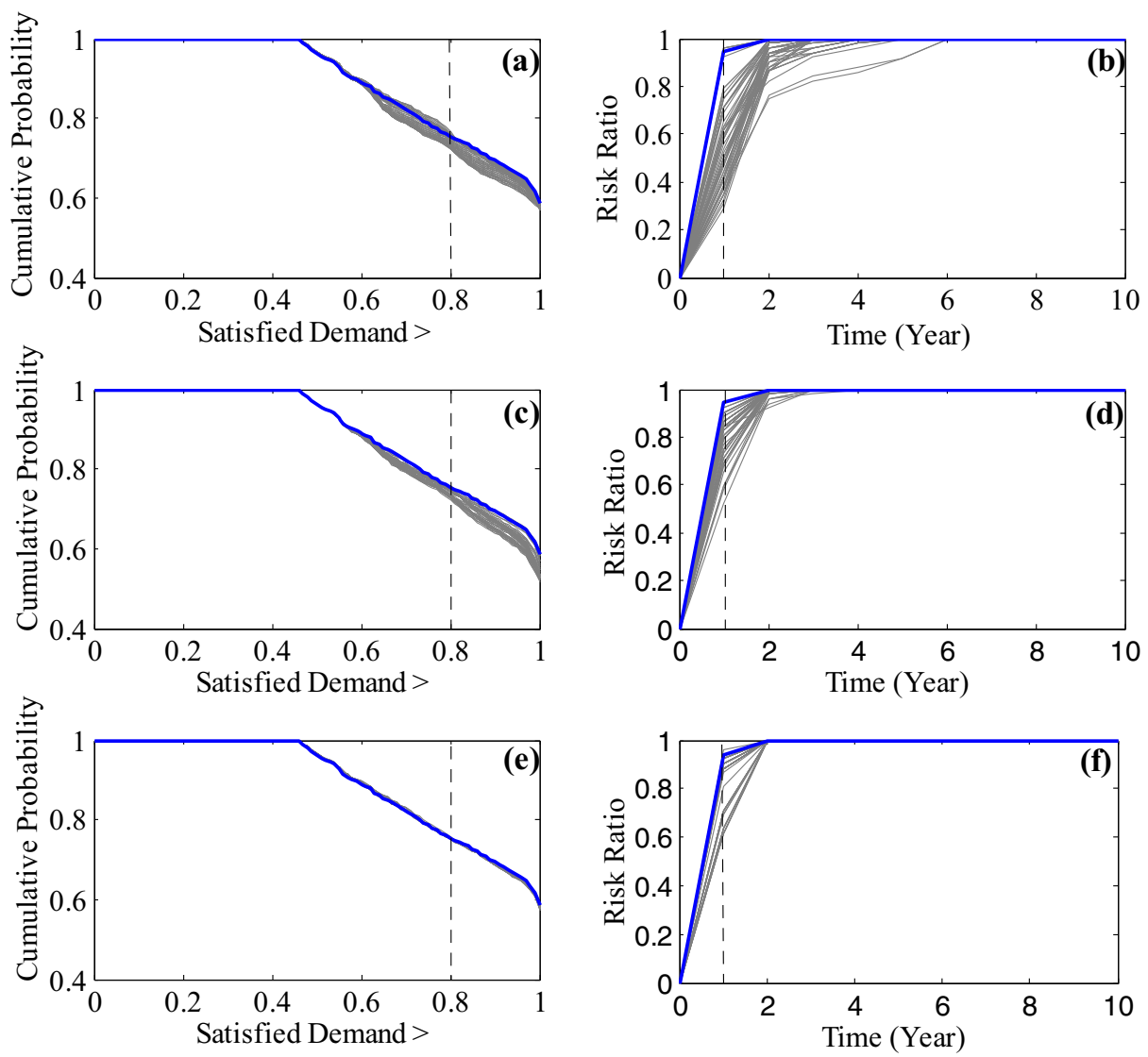

Fig. 4 (a) Cumulative probability of different satisfied demands of IAS and FASs generated with gain function; (b) The risk ratio of IAS and FASs generated with gain function; (c) Cumulative probability of different satisfied demands of IAS and FASs generated with correlation function; (d) The risk ratio of IAS and FASs generated with correlation function; (e) Cumulative probability of different satisfied demands of IAS and FASs generated with least square function; (f) The risk ratio of IAS and FASs generated with least square function; The FASs are shown in gray lines; IAS is shown in blue line. With the same satisfied demand, higher cumulative probability means a better performance; and with the same time duration, lower risk ratio indicates a better performance 
Almost all the FAS_CR are with low results of CP compared with IAS (Fig. 4c), while the RR results are better than IAS (Fig. 4f), meaning that correlation function has an effect on reducing the risk of continuous water shortage occurrence, but has no improvement of the satisfied demand. Fig. 4e illustrates that FAS_LS (feedback allocation solution generated with least square function) is almost like IAS, the least square function made little improvement or degradation of the assurance rate of satisfied demand (Fig. 4e), while Fig. 4f shows the function has an effect on reducing the risk of continuous water shortage occurrence, as the risk ratio lines of FAS_LS are lower than the initial one.

To see more details of all the results, we take a certain point where the satisfied demand is $80 \%$ (CP80\%) as an example. The CP80\% of IAS is 0.754 (Table 1), meaning the assurance rate of that, equal or larger than $80 \%$ demand has been satisfied, is $75.4 \%$. As for FAS_GF, with different function parameters, the range of CP80\% is from 0.72 to 0.764 , among which the best result is 0.01 larger than the results of IAS. In the contrast, FAS_CR and FAS_LS had little improvement, with a value range of $0.72-0.755$ and $0.752-0.758$, respectively, in which the best results were 0.001 and 0.004 , respectively, larger than IAS. Moreover, FAS_CR had a wide variation range, however, almost values were less than the initial one. FAS_LS had a narrow variation range, and the best result $(0.758)$ was higher than the one from FAS_CR $(0.755)$ and lower than the one from FAS_GF (0.764).

We also took the risk ratio of continuous water shortage happening in one year $\left(\mathrm{RR}_{1 \text { year }}\right)$ as an example to see the details in Fig. 4b, d, and f. The $\mathrm{RR}_{1 \text { year }}$ of IAS was 0.94 (Table 1), which is a very high risk ratio, indicating that continuous water shortage could occur in almost every single year. However, all feedback allocation methods improved it significantly. The variation range of FAS_GF, FAS_CR and FAS_LS was 0.23-0.96, 0.52-0.94, and 0.62-0.96, respectively. Among the three feedback functions, the gain function was the best one to decrease the risk ratio, as its best one can lower the $\mathrm{RR}_{\text {lyear }}$ to 0.23 , while the best one of CR and LS was 0.52 and 0.62 , respectively.

As shown in Fig. 4 and Table 1, GF was selected as the best feedback function. Moreover, the best parameters of every function were analyzed next, the optimization range of function parameters were shown in section 2.4 (GF optimized the parameters $K r$ and $K d$, with a range from 0 to 2, and -1-1, respectively; CR optimized the series size, from 2 to 60 time steps; LS was the same as $\mathrm{CR}$ ). We used the $\mathrm{CP}_{80 \%}$ and $\mathrm{RR}_{1 \text { year }}$ as an evaluation index. Every FAS generated by different functions and different function parameters was a point in Fig. 5. The value of $\mathrm{CP}_{80 \%}$ is $\mathrm{x}$ axis, and the value of $\mathrm{RR}_{1 \text { year }}$ is $\mathrm{y}$ axis. Larger $\mathrm{CP}_{80 \%}$ and smaller $\mathrm{RR}_{1 \text { year }}$ mean a better solution. As shown in Fig. 5, the best solution in every feedback function is highlighted by a bigger mark. When $K r=0.9, K d=0$, GF generated the best solution whose $\mathrm{CP}_{80 \%}$ was 0.764 , and $\mathrm{RR}_{1 \text { year }}$ was 0.635 ; when time steps $=3, \mathrm{CR}$ generated the best solution whose $\mathrm{CP}_{80 \%}$ was 0.755 , and $\mathrm{RR}_{1 \text { year }}$ was 0.596 ; when time steps $=2, \mathrm{CR}$ generated the best

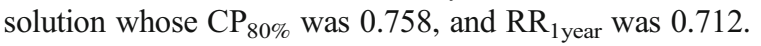

Table 1 The $\mathrm{CP}_{80 \%}$ and $\mathrm{RR}_{1 \text { year }}$ results of IAS and FASs

\begin{tabular}{ccr}
\hline & $\mathrm{CP}_{80 \%}$ & $\mathrm{RR}_{1 \text { year }}$ \\
\hline IAS & 0.754 & 0.94 \\
FAS_GF & {$[0.720,0.764]$} & {$[0.23,0.96]$} \\
FAS_CR & {$[0.720,0.755]$} & {$[0.52,0.94]$} \\
FAS_LS & {$[0.752,0.758]$} & {$[0.62,0.96]$} \\
\hline
\end{tabular}


Risk ratio of accicident

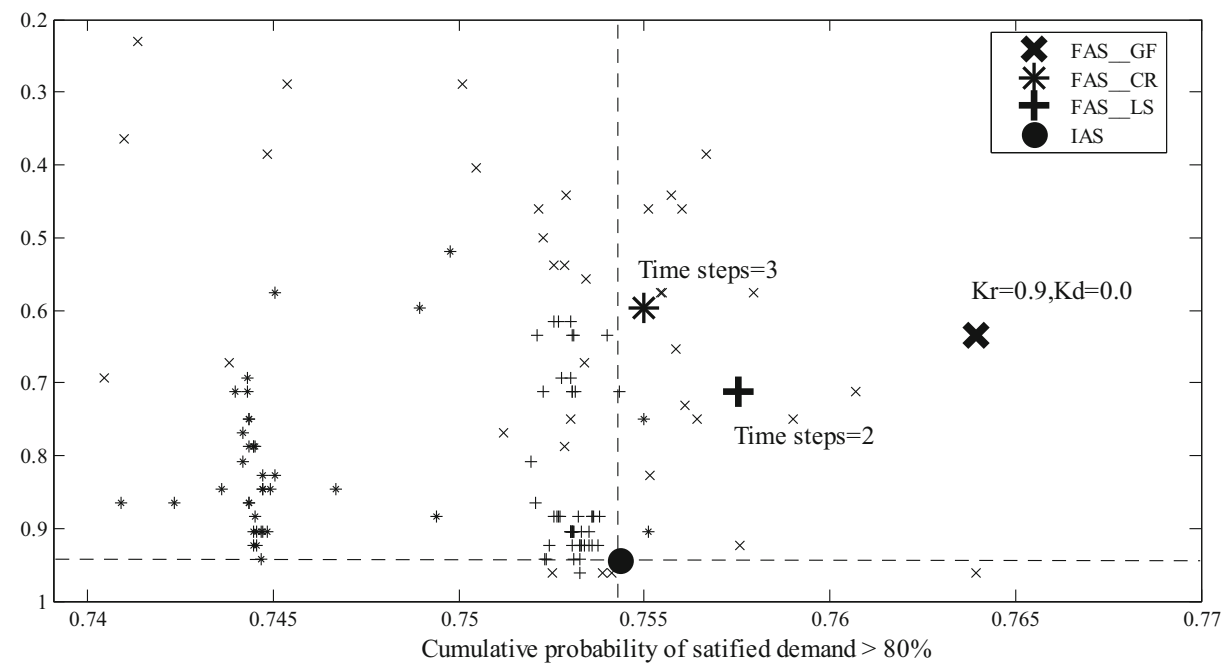

Fig. 5 The $\mathrm{CP}_{80 \%}$ and $\mathrm{RR}_{1 \text { year }}$ results in different feedback function and different function parameters

As motioned before, FAS, generated using the ASFA framework, improved the performance of the initial solution. However, the improvement was limited. For example, if the management target was increasing $\mathrm{CP}_{80 \%}$ to 0.8 , and lowering $\mathrm{RR}_{1 \text { year }}$ to 0.7 , applying the feedback allocation method can hardly achieve these goals. Further water resources management engineering was required, such as diverting water resources. So we further explored how much diverted water was needed to achieve the example goal with the initial method and ASFA.

Assuming there was diverted water from 0 to $4 \mathrm{~m}^{3} / \mathrm{s}$, we allocated the water resources with all four methods to analyze how much diverted water was required to meet the management target. We can see in Fig. 6a-g that with larger diverted water resources, CP of every satisfied demand increased significantly. As indicated from Fig. 6b-h, RR was generally lowered with larger diverted water resources. It is an expected result, as more available water resources would make a better allocation solution.

However, differences between different allocation methods were also significant. For example, to achieve the same management goal that $\mathrm{CP}_{80 \%}$ was up to 0.8 (the red points in Fig. $6 \mathrm{a}, \mathrm{c}, \mathrm{e}$, and g), IAS required $1.0 \mathrm{~m}^{3} / \mathrm{s}$ diverted water, while FAS_GF needed $0.6 \mathrm{~m}^{3} / \mathrm{s}$, almost half the amount of the initial transfer demand was cut off. As for FAS_CR and FAS_LS, $0.8 \mathrm{~m}^{3} / \mathrm{s}$ diverted water was required to achieve the goal, less than IAS, and more than FAS_GF.

As for risk ratio, much more diverted water made lower RR, however, FAS_GF and FAS_LS were the results that lowered RR more significantly. Specifically, to achieve the management goal that $R_{1 \text { year }}$ was less than 0.7 (the red points in Fig. $6 b, d, f$, and $h$ ), $1.8 \mathrm{~m}^{3} / \mathrm{s}$ diverted water was required by IAS, while no diverted water was needed by FAS_GF, and $0.8 \mathrm{~m}^{3} / \mathrm{s}$ was needed by both FAS_CR and FAS_LS.

The feedback allocation method can cut off the demand of diverted water resources significantly to achieve the same management goal, and moreover, GF has a better effect than other two feedback functions. 

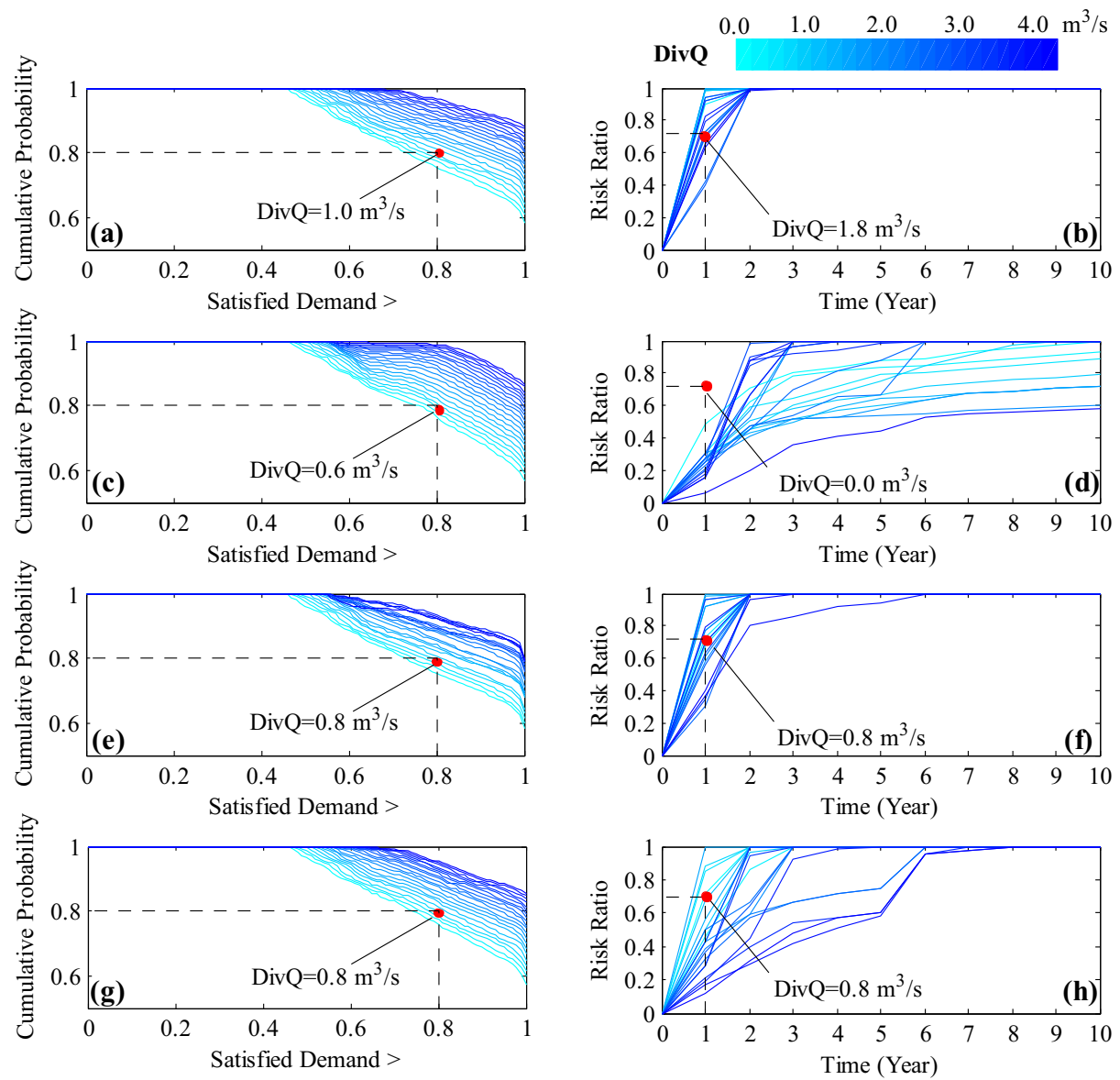

Fig. 6 Evaluation of allocation solutions with different amounts of diverted water resources. (a) Cumulative probability curves of satisfied demand of IAS with different diverted water; (b) Risk ratio curves of IAS with different diverted water amounts; (c) Cumulative probability curves of satisfied demand of FAS GF with different diverted water amounts; (d) Risk ratio curves of FAS_GF with different diverted water amounts; (e) Cumulative probability curves of satisfied demand of FAS_CR with different diverted water amounts; (f) Risk ratio curves of FAS_CR with different diverted water amounts; (g) Cumulative probability curves of satisfied demand of FAS_LS with different diverted water; and (h) Risk ratio curves of FAS_LS with different diverted water amounts

\section{Discussion}

Results show that the ASFA framework did a better job comparing the initial allocation solution in the case study area. Moreover, the ASFA framework provided another perspective to address water management problem in the context of uncertainty. In addition to the reduction of uncertainty or strengthening the robustness of solutions, it is also meaningful to put efforts to adjust the solution quickly and effectively by collecting and processing real-time information.

There is also a complementary relationship between the reduction of uncertainty and ASFA framework. The former commonly pays attention to the correction of long time series. While the ASFA framework focuses more on real-time adjustment. The "feedback" part and the "adjustment" part in the ASFA framework consider real-time information only, it is easy to be 
trapped in local optimal solution: in order to satisfy demand at a certain time point, water resource was allocated in the earlier time, causing much severer water shortage in the later period. That is why we generated an initial allocation solution first, which ensures that the water resources can be allocated properly generally in the whole period. Results from nonstationary studies provide more precise results of long-time future characters, which is helpful to generate a better initial allocation solution. Then, the ASFA framework can focus on realtime adjustment and avoid being tapped in local optimal solution.

For robust decision making, it is more suitable for managers to making solid decisions, such as construction of reservoir or building a management regulation. Such decisions work for a long time, but are costly if some adjustment is needed. By contrast, ASFA framework can be more widely used in generating water allocation solutions, which is less costly and has more space for adjustment.

\section{Conclusion}

This paper presents an "assumption-simulation-feedback-adjustment" (ASFA) route for real-time correction of water resources allocation. In the ASFA framework, the performance of initial allocation solution is a feedback to generate a gain value by feedback function for correcting a feedback solution. Three different feedback functions: gain function, correlation function, and least square function, are applied for comparison. Results show that the ASFA framework with gain function has a better performance than others, as it generates a solution with higher assurance rate and lower risk ratio of continuous water shortage. Results further indicate that applying the ASFA framework with gain function can achieve the management goal with fewer requirements of diverted water resources. The study indicates the ASFS framework has the ability to use water resources more efficiently under future uncertainty. It has also potential to be applied in other regions to assist water sectors make better management decisions.

Acknowledgements The research is financially supported by National Key R\&D Program of China (2017YFC0405900), National Natural Science Foundation of China (Grant No. 91547202, 51210013, 51479216, 51509127), the Chinese Academy of Engineering Consulting Project (2015-ZD-07-04-03), the Project for Creative Research from Guangdong Water Resources Department (Grant No. 2016-07, 2016-01), Research program of Guangzhou Water Authority(2017), the State Scholarship Fund of China(Grant No.2017063871).

\section{Compliance with Ethical Standards}

\section{Conflict of Interest None.}

Open Access This article is distributed under the terms of the Creative Commons Attribution 4.0 International License (http://creativecommons.org/licenses/by/4.0/), which permits unrestricted use, distribution, and reproduction in any medium, provided you give appropriate credit to the original author(s) and the source, provide a link to the Creative Commons license, and indicate if changes were made.

\section{References}

Adamowski JF (2008) Peak daily water demand forecast modeling using artificial neural networks. J Water Resour Plan Manag 134(2):119-128 
Bankes SC (2002) Tools and techniques for developing policies for complex and uncertain systems. Proc Natl Acad Sci 99(suppl 3):7263-7266

Bayazit M (2015) Nonstationarity of hydrological records and recent trends in trend analysis: a state-of-the-art review. Environ Proc 2(3):527-542

Blöschl G, Reszler C, Komma J (2008) A spatially distributed flash flood forecasting model. Environ Model Softw 23(4):464-478

Chavent G (1979) Identification of distributed parameter systems: about the output least square method, its implementation, and identifiability. IFAC Proc 12(8):85-97

Cohn TA, Lins HF (2005) Nature's style: Naturally trendy. Geophys Res Lett 32(23)

Cooper ES, Dance SL, Garcia-Pintado J, Nichols NK, Smith PJ (2018) Observation impact, domain length and parameter estimation in data assimilation for flood forecasting. Environ Model Softw 104:199-214

Coulibaly P, Baldwin CK (2005) Nonstationary hydrological time series forecasting using nonlinear dynamic methods. J Hydrol 307(1-4):164-174

Davijani MH, Banihabib ME, Anvar AN, Hashemi SR (2016) Multi-objective optimization model for the allocation of water resources in arid regions based on the maximization of socioeconomic efficiency. Water Resour Manag 30(3):927-946

Elferchichi A, Gharsallah O, Nouiri I, Lebdi F, Lamaddalena N (2009) The genetic algorithm approach for identifying the optimal operation of a multi-reservoirs on-demand irrigation system. Biosyst Eng 102(3):334-344

Galloway GE (2011) If stationarity is dead, what do we do now? J Am Water Resour Assoc 47(3):563-570

Ghiassi M, Zimbra DK, Saidane H (2008) Urban water demand forecasting with a dynamic artificial neural network model. J Water Resour Plan Manag 134(2):138-146

Groves DG, Lempert RJ (2007) A new analytic method for finding policy-relevant scenarios. Glob Environ Chang 17(1):73-85

Heidari A, Saghafian B, Maknoon R (2006) Assessment of flood forecasting lead time based on generalized likelihood uncertainty estimation approach. Stoch Environ Res Risk Asses 20(5):363-380

Herman JD, Zeff HB, Reed PM, Characklis GW (2014) Beyond optimality: multistakeholder robustness tradeoffs for regional water portfolio planning under deep uncertainty. Water Resour Res 50(10):7692-7713

Jain A, Varshney AK, Joshi UC (2001) Short-term water demand forecast modelling at IIT Kanpur using artificial neural networks. Water Resour Manag 15(5):299-321

Lempert RJ, Groves DG (2010) Identifying and evaluating robust adaptive policy responses to climate change for water management agencies in the American west. Technol Forecast Soc 77(6):960-974

Liu D, Chen X, Lou Z (2010) A model for the optimal allocation of water resources in a saltwater intrusion area: a case study in Pearl River Delta in China. Water Resour Manag 24(1):63-81

Liu Z, Guo S, Zhang H, Liu D, Yang G (2016) Comparative study of three updating procedures for real-time flood forecasting. Water Resour Manag 30(7):2111-2126

Madsen H, Skotner C (2005) Adaptive state updating in real-time river flow forecasting - a combined filtering and error forecasting procedure. J Hydrol 308(1):302-312

Milly PC, Betancourt J, Falkenmark M, Hirsch RM, Kundzewicz ZW, Lettenmaier DP, Stouffer RJ (2008) Stationarity is dead: whither water management? Science 319(5863):573-574

Morshed J, Kaluarachchi JJ (2000) Enhancements to genetic algorithm for optimal ground-water management. J Hydrol Eng 5(1):67-73

Nakagawa T, Koyanagi Y (1982) Experimental Data Analysis by the least square method. Tokyo Daigaku Shuppankai, 99

Nouiri I (2014) Multi-objective tool to optimize the water resources management using genetic algorithm and the Pareto optimality concept. Water Resour Manag 28(10):2885-2901

Rahman A, Charron C, Ouarda TB, Chebana F (2018) Development of regional flood frequency analysis techniques using generalized additive models for Australia. Stoch Environ Res Risk Asses 32(1):123-139

Raje D, Mujumdar PP (2010) Constraining uncertainty in regional hydrologic impacts of climate change: Nonstationarity in downscaling. Water Resour Res 46(7)

Schmocker-Fackel P, Naef F (2010) More frequent flooding? Changes in flood frequency in Switzerland since 1850. J Hydrol 381(1):1-8

Serinaldi F (2015) Dismissing return periods. Stoch Environ Res Risk Asses 29(4):1179-1189

Shao Q, Li M (2011) A new trend analysis for seasonal time series with consideration of data dependence. J Hydrol 396(1):104-112

Steinschneider S, Brown C, (2012) Dynamic reservoir management with real-option risk hedging as a robust adaptation to nonstationary climate. Water Resour Res 48(5)

Westra S, Thyer M, Leonard M, Kavetski D, Lambert M (2014) A strategy for diagnosing and interpreting hydrological model nonstationarity. Water Resour Res 50(6):5090-5113

Zahraie B, Tavakolan M (2009) Stochastic time-cost-resource utilization optimization using nondominated sorting genetic algorithm and discrete fuzzy sets. J Constr Eng Manag 135(11):1162-1171 